www.nature.com/ejcn

\title{
EDITORIAL
}

\section{EJCN: 25 years of progress}

European Journal of Clinical Nutrition (2013) 67, 423; doi:10.1038/ ejcn.2013.57

In its present form the European Journal of Clinical Nutrition (EJCN) has now reached its 25 th year of publication. It started many years before as the Journal of Human Nutrition, with the intention of providing 'a forum for all those concerned with the science of human nutrition and with the application of that science to the feeding of people in health and disease. ${ }^{1}$ In 1982, the decision was taken to separate the journal into two volumes-Human Nutrition: Applied Nutrition and Human Nutrition: Clinical Nutrition. The idea behind this was to retain Human Nutrition: Applied Nutrition as the key publication outlet for research on measurement of dietary intake, food composition, nutrition education, and dietetics and social nutrition, while creating a separate outlet for research from the emerging field of clinical nutrition. In 1988, these two journals were combined to form EJCN, starting with volume 42. John Waterlow was the founding Editor and Jo Hautvast, the Chairman of the Editorial Board. John Garrow, Jaap Seidell and Prakash Shetty took over editorships during the years 1990-2011 and together have played a crucial role in the growth, popularity and success of the journal.

EJCN covers a broad spectrum of subjects in nutrition and metabolism, from epidemiological to clinical research. ${ }^{2}$ In 1988 , EJCN published a total of 120 articles, $28 \%$ of which focused on epidemiology and public health nutrition, $26 \%$ on research in the fields of lipids (including cardiovascular health) and carbohydrates (including diabetes mellitus), and only $10 \%$ on clinical nutrition (for example, parenteral and enteral nutrition). The number of articles published during the journal's history has fluctuated, totaling 180 in 2012. In addition, the portfolio of research topics addressed has changed. The number of articles on minerals, trace elements, vitamin $D$ and bone health has increased, from $\sim 6 \%$ in 1988 to nearly $15 \%$ of all articles published in 2008, as has the number of articles on maternal nutrition, infants and children, increasing from 8 to $18 \%$. Submissions on epidemiology, public health nutrition and clinical nutrition, body composition and energy expenditure have remained fairly consistant during this time, while research on lipids and foods and health has decreased. This short overview reflects the broad scope of EJCN. All of the fundamental issues of clinical nutrition have been and continue to be covered. It is a matter of science that interests change with time and different focuses become apparent. This is also the result of research facilities and funding. For example, $\sim 20$ years ago nutritional epidemiology was a recognized challenge and large, well-funded, multi-centered studies were started throughout Europe. The high productivity in this area is reflected by the high volume of articles received on epidemiological research. The recent hype on vitamin D and maternal nutrition is also well reflected by the increasing number of articles published on these issues over recent years in EJCN.

EJCN was founded as a European journal. In 1988, 65\% of the published articles were submitted by authors from Europe, followed by those from North America (9\%), South East Asia (9\%), Africa (7\%), Australia/New Zealand (4\%), Middle and South America (3\%) and the Middle East (3\%). Within 25 years of publication, contributions from North America, Australia/New Zealand and South East Asia have steadily increased (to 18\%, $10 \%$ and $15 \%$, respectively, of the articles published in 2012), with numbers from Middle and South America and the Middle East remaining constant. In contrast, contributions from Europe and, unfortunately, Africa have decreased (to $51 \%$ and $1 \%$, respectively). As an Editor, being faced with an increasing number of submissions from non-European countries is a good indication that the journal has, and still is, becoming more and more international. For the future, however, we must consider strategies to attract authors from the so far under-represented countries. Owing to the regional spread of submissions, the majority of our submissions focus on problems of affluence rather than on poverty and malnutrition. In 2013 , I hope to commission a special issue to bring to the fore discussion on the nutritional problems faced by those in areas where poverty is an issue.

To celebrate the evolution of the journal during the 25 years it has published as EJCN, I have put together this special Anniversary issue, which includes contributions from the majority of our Editorial Board members. I feel it is an exceptional issue covering nearly the whole spectrum of clinical nutrition. The contributions reflect the high standard of the journal, as well as the broad interests and qualifications of the Board members. I would like to thank all authors for their enthusiasm and their input. Producing this issue together had the added value of creating somewhat of a 'community feeling' among our Board members. As you are aware, EJCN is not related to an association or a specific society. Our strength instead is our scientific community, which obviously is alive.

I would also like to take this opportunity to thank our distinguished body of reviewers, who are a central part of our community and whose steady input keeps the journal going. Hopefully, the community feeling we have created among the Board and our team of reviewers will be transmitted to our readers and also to forthcoming authors who want to join the EJCN community.

\section{CONFLICT OF INTEREST}

The author declares no conflict of interest.

MJ Müller

Institute for Human Nutrition and Food Science, Christian-Albrechts-University of Kiel, Kiel, Germany E-mail: mmueller@nutrfoodsc.uni-kiel.de

\section{REFERENCES}

1 Shetty P. Eur J Clin Nutr 2011; 65: 1-2.

2 Müller MJ. Eur J Clin Nutr 2012; 66: 1-2. 